\title{
SAUDAÇÃO DE BARBOSA LIMA SOBRINH'O AO HISTORIADOR JOSÉ HONÓRIO RODRIGUES $\left(^{\star}\right)$.
}

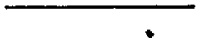

BARBOSA LIMA SOBRINHO

Da Academia Brasileira de Letras.

\section{NO PASSADO E NO PRESENTE A RESPOSTA PARA O FUTURO.}

Sr. José Honório Rodrigues:

Parece-me ainda ouvir as últimas palavras de vosso discurso: — "Porventura não é maior quem está à mesa? Eu, porém, entre vós - acabastes mesmo de dizer - sou como aquêle que serve".

Custa-nos um pouco relembrar, neste ambiente de festas, com todos êsses dourados, o momento em que essas palavras foram pronunciadas. Mas não esqueçamos que, quem as disse, foi o próprio Cristo, servindo aos apóstolos a ceia da Eucaristia .

Deixemos, pois, de lado o burel de franciscano. Sois bastante afirmativo para que nos contentemos com a letra de São Lucas. Tanto mais quando os 32 votos que obtivestes, numa das belas consagrações já registradas nesta Academia foram homenagem à vossa bravura de combatente, à intrepidez desinteressada dos vossos pronunciamentos e ao mérito de uma obra de cultura, rara em nosso País e até mesmo em vossa idade, não obstante os cabelos brancos com que vos disfarçastes, pois que os ostentais desde os quarenta anos. Nem me parece que as Academias, por mais comportadas que possam ou pretendam ser, aceitem de boa vontade uma tarefa de concordância e de assentimento. Não vejo por que não se ajustarão elas a atitudes de renovação, a palavras de rebeldia, atentas às vozes inumeráveis, que procuram interpretar e traduzir as aspirações das novas correntes do pensamento brasileiro. Sempre me pareceu que, para essa tarefa

(*). - Saudação de Barbosa Lima Sobrinho a José Honório Rodrigues, que tomou posse a 5 de dezembro de 1969 na Academia Braslleira de Letras, da Cadeira de que é patrono Tavares Bastos. Reprodução, devidamente autorizada, do texto publicado no "O Jornal", de 7 de dezembro de 1969, página $8,2^{\circ}$ caderno, Rlo de Janelro. (Nota da Redação). 
as Academias são mais úteis, e mais acessíveis do que os grupos literários, até mesmo pelo desencôntro das tendências com que se foram constituindo, estranhas e indiferentes a definições e a preocupações sectárias.

O próprio Graça Aranha, quando vivia a sua fase de lua-de-mel com a Academia, que o elegera sem livros publicados, confiada, apenas, na sua estuante vocação literária, dissera, no discurso com que recebera Souza Bandeira, que a Academia tinha horror aos princípios, "principalmente aquêles que a privem de liberdade", reportando-se à liberdade das eleições é à ausência de qualquer limitação na substituição dos escritores. E observava então, com aquela agudeza de espírito que nunca lhe faltou, que a "Academia somos todos nós, a incoerência de sua própria existência, o desencanto de nossas ilusões individuais, a divergência de nossas idéias o absoluto de cada um formando o relativo de todos. A verdade, concluía êle, são quarenta bôcas que se contradizem".

Que se contradizem e discutem. Cada qual mais cioso de si mesmo e de suas convicções. Mas não tenhais receio dêsse panorama. Nem vos estimuleis demasiadamente com êle. Longe de mim a idéia de vos apresentar a Academia como um tablado de luta livre. Embora já tivéssemos tido - e vêde como a Academia é caprichosa e irregular - o que eu chamaria a nossa fase de grandeza, com os dois em:nentes contendores, que davam por empatado o seu prélio antigo, quando sentiram a inutilidade de seus esforços, pois que haviam perdido sentido os gestos de provocação e as palavras injứriosas, que um não chegava a ver e o outro não podia ouvir. Mas isso já passou e eram mais manifestações de temperamentos insofridos do que costume ou necessidade da Academia. Se é que os adversários não agiam apenas com o desêjo íntimo de se divertirem. Mesmo quando já se torna difícil fazer o cálculo da própria idade, custa sacrificar as exigências e o alvoroço da mocidade.

Não há, pois, que abandonar posições definidas. Basta não criar obstáculos a uma convivência, que vai durar tôda a vida e que será, de certo, agradável, quando as outras atividades fôrem cessando e reste apenas esta, a do gôsto pelas letras ou a do interêsse pela cultura. Mais que o nível de educação individual, influirá a vitaliciedade das investiduras. Enquanto a prezarmos e a quisermos conservar, iremos esquecendo o mal estar de alguma eleição, as palavras que talvez não tenham sido felizes, os mil e um agravos de uma convivência, que acaba sendo quotidiana. Apesar de tudo, não há aqui lugar para o palavrão, que já pagamos para ouvir nos teatros, quando aconteça que êle não nos surpreenda na vozinha infantil de nossos netos. Na verdade, são quarenta bôcas que se contradizem com ener- 
gia, difíceis de coordenar nas votações, quando escasseiam os denominadores comuns de entendimento ou se tornem êles difíceis de perceber ou de adivinhar. Quarenta bôcas que se contradizem, mas que, na verdade, se estimam.

Não vos faltará oportunidade para essa experiência. Não raro tereis dúvida quanto à atitude que deveis tomar se a da conformidade, se a da revolta. O essêncial, dir-vos-ei, é não se conformar. Mas também não esquecer que o vínculo que acaba de vos ser impôsto, é um vínculo indissolúvel.

Carlos de Laet gostava de falar nos filtros acadêmicos, que êle chamava "triaga", um específico antigo contra mordeduras venenosas. Eu recomendaria antes beberagens, que contivessem doses maciças de tolerância. Porque há que admitir aqui a verdade de cada um, de que falava Pirandello. E quando todos êsses recursos viessem a falhar não nos faltariam ainda tradições alentadoras. Com a tradição que nos ficou da cadeira 35, a cadeira que os dois Rodrigo Octávio dignificaram.

\section{Os dois Rodrigo Octávio.}

De Rodrigo Octávio Filho vos direi que me impressionou sempre a circunstância, de que êle não houvesse pleiteado, ainda em vida do pai, alguma das que se iam verificando na Academia. Vivera intensamente a fase simbolista no Brasil, ao lado de mestres e companheiros como Mário Pederneiras, Felipe de Oliveira e Álvaro Moreyra. Militara num grupo inovador e atuante, como havia sido a revista Fon-Fon, quando as sílabas onomatopaicas da buzina dos automóveis pareceria, por si só nas letras nacionais, uma convocação subversiva, mais adiante renovada pelo periódico Klaxon. Notemos que o livro de poemas de Rodrigo Octávio Filho Alameda Noturna, aparecera em 1922. Velhos Amigos, outro livro de estudos literários, surgira também em vida do velho Rodrigo Octávio, sem falar em numerosas conferências, que iam assinalando a presença do môço Rodrigo Octávio nas letras brasileiras.

Suponho, e já ouvi impressões nesse sentido, que havia uma espécie de entendimento entre os dois Rodrigo Octávio, a fim de que o filho se guardasse para a própria cadeira do velho Rodrigo Octávio. O que poderia parecer constrangedor, com a espera de uma vaga, que só se abrira com a morte do próprio pai do candidato. Mas não custamos a compreender que nunca houve aspirante mais interessado no adiamento da sucessão. E ao velho Rodrigo Octávio sorriria a 
idéia de vir a substituído pelo próprio filho. Pude assim acreditar que, se derrotado no pleito a que se apresentou, para a vaga de Rodrigo Octávio, o filho teria desistido da Academia. Não que a menosprezasse. Mas o atrativo da sucessão paterna era, para êle, uma razão mais poderosa que o próprio ingresso na Academia.

Fomos compreendendo melhor êsses sentimentos, durante os 24 anos em que aqui tivemos a companhia de Rodrigo Octávio Filho. E já ia dizendo a companhia gentil, colhido quase de surprêsa por um adjetivo insinuante. Porque embora Rodrigo Octávio Filho fizesse questão de relacionar o que êle chamava "as provas" de sua idade, como o nascimento do bisneto e as operações a que o tempo o condenara, sobretudo a de catarata, que tanto o fêz sofrer (não obstante sua heróica resignação), a verdade é que êle nunca perdeu a graça física da mocidade, na elegância aprumada e viril. Como também não abriu mão de um otimismo tranquiilo, de um sorriso acolhedor, de um ar prazenteiro, que era o segrêdo de sua simpatia, se não esquecermos a indulgência de seus julgamentos e a ausência de qualquer maledicência - virtude rara, até mesmo surpreendente, numa sociedade de homens de letras.

Há exemplos de dedicação filial em outras instituições culturais. Na Academia Francesa, por exemplo, cita-se o caso de Henri Houssaye que, eleito em 1894, não pôde deixar de exprobrar a atitude dos companheiros, que não haviam feito justiça a seu pai, Arsène Houssay, que também merccera a Academia. Mas Arsène Houssaye publicara uma sátira difícil de esquecer ou de perdoar, a Histoire $d u$ quarante-et-unième fauteuil de l'Academie, a relação dos nomes ilustres que haviam ficado à margem da láurea acadêmica. De qualquer forma, era uma cena comovedora, o filho a protestar, na tribuna acadêmica, contra a injustiça que o pai sofrera, e Arsène Houssaye, já octogenário, presente à recepção do filho e, provàvelmente, mais agradecido à Academia do que se houvesse sido êle próprio o escolhido.

Aqui, na Academia Brasileira, o sentimento filial pôde se expandir sem agravos e sem ressentimentos. A eleição do filho completou o quadro das afeições, dando a impressão de uma continuação sorridente e tranquiila do próprio fundador da cadeira .

Quando me defronto à bibliografia dos dois Rodrigo Octávio, o que me chama a atenção é a presença dos mesmos temas ou dos mesmos assuntos. Os estudos de Rodrigo Octávio Filho, em Figuras do Império e da República, focalizavam o Marquês de Barbacena, Osório, Tavares Bastos, Prudente de Morais, Ubaldino do Amaral, que estavam relacionados, de alguma forma, com a vida do velho Rodrigo Octávio. O Visconde de Barbacena, filho do Marquês, havia 
sido cliente de seu escritório de advogado e o próprio Rodrigo Octávio escrevera quase como obra de causídico, o Felisberto Caldeira, o contratador de diamantes, para desagravo de tôda a família. Osório fôra um ídolo do Partido Liberal, a que se vinculavam os ascendentes do velho Rodrigo Octávio. Prudente de Morais, como Tavares Bastos, já figurava no livro de memórias de Rodrigo Octávio, $\mathrm{Co}^{-}$ ração Aberto. Ubaldino do Amaral havia sido seu companheiro de escritório.

Até mesmo no estudo da Constituinte de 1823 , encontraremos pai e filho reunidos, o primeiro no Congresso Nacional de História de 1914, o segundo no Congresso Nacional de História de 1931. Não se limita Rodrigo Octávio Filho a citar a monografia do pai: identifica-se com suas teses. Defende a primeira assembléia brasileira contra a prepotência impetuosa de Pedro I. Exalta os Andradas perseguidos e deportados, tratados, aliás, de anarquistas para baixo, nas proclamações incendiárias do Imperador.

Assinalastes, com a proficiência de um historiador, a vocação liberal da cadeira que viestes ocupar em nossa companhia. Eu gostaria de acrescentar, a êsse quadro, a satisfação que os dois Rodrigo Octávio não ocultavam: a de pertencerem a esta Casa. A vida exigiu dêles outras tarefas, de que não souberam ou não puderam fugir. Mas percebia-se que só se sentiam realizados nesta Academia. Não estava em êrro Rodrigo Octávio Filho, quando descrevia o pai como um poeta, que continuasse até o último alento "sensível, triste, imaginativo, claro no estilo e elevado no pensamento, a conversar de vez em quando com a sua poesia a poesia que nascera com êle". Les Raphsodies, provavam essa afeição, publicadas quando o velho Rodrigo Octávio já havia ultrapassado os 70 anos de uma vida, quase tôda consumida em outras tarefas, exigentes e exaustivas.

De Rodrigo Octávio Filho se poderia dizer a mesma coisa: sentia-se um exilado, fora das letras e dos assuntos literários. As recordações que o fascinavam eram as da mocidade quando vivera em companhia de amigos, no culto de Rodemback, que o atraíra a êle e a Olegário Mariano - mas Olegário Mariano se conservara fiel até o fim e Rodrigo Octávio Filho não pudera resistir às atividades dispersivas, que o foram assediando. A Academia fôra para êle, uma espécie de Shangrilá, o seu enlêvo e a sua glória .

Graças a Rodrigo Octávio Filho, a cadeira 35 foi a que conservou por mais tempo a memória, e eu quase diria a presença do fundador. A amizade acabou superando a longevidade do fundador que mais viveu e que foi o nosso companheiro Magalhães de Azeredo. Nem se pode separar agora os dois ocupantes da cadeira 35, quando ambos concorreram para a formação de seu patrimônio. 
Porque não chegou a haver um caso de herança ou de sucessão: foi antes um caso de integração.

Gostaria, por isso, de vos proclamar o segundo ocupante da cadeira 35, reunindo-as numa só pessoa os dois Rodrigo Octávio. O mais belo florão das amizades terrenas emoldura a vossa cadeira. Não sei se devemos exaltar o pai que inspirou tal devotamento ou o filho, que fêz dessa devoção um objetivo, que mais pareceria um culto ou uma religião.

Essa a sucessão que recolheis, sr. José Honório. Fostes discípulo de um e amigo do outro. Sabeis avaliar bem o que vale a vossa cadeira, sobretudo quando imaginais que a afeição, que ela inspirou a Rodrigo Octávio Filho, sabia guardar-se num escrúpulo de sobriedade e discrição, que ainda mais o engrandecia.

\section{Não é bem uma cadeira de historiador.}

Não é bem uma cadeira de historiador a Cadeira 35. Nem há aqui cadeiras cativas para qualquer gênero literário. Tudo depende do acaso ou das pressões eleitorais. Mas Literatura e História se entendem bem. Basta recordar que para os antigos compunham a mesma família das Musas, com a literatura, a história, a tragédia a elegia, a poesia lírica, misturadas ou convivendo com a dança, a música e até a astronomia, que ainda não começara a aprender as matemáticas. Clio acumulava a história com a poesia épica, para o louvor de guerreiros, que ainda não se resignavam com a burocracia dos Estados-Maiores. Depois, a epopéia ficou de lado e os historiadores compensaram a união antiga, exagerando a descrição das guerras e a influência dos reis e dos governos. Mesmo assim, tiveram acesso fácil nas corporações literárias. Não há talvez, um só fauteuil da Academia Francesa, que não tenha servido, em algum momento, para a exaltação de historiadores como Lavisse, Julian, Hanotaux, Massom, Bainville, Grousset e muitos muitos outros.

Nem sois apenas um historiador, sr. José Honório. Escreveis bem, com uma precisão e energia de bom quilate, em períodos claros e concisos, que não se embaraçam com as sutilezas da filosofia, nem se assusta com as exigências de uma conceituação exata. Mas o que na verdade vos caracteriza, é que não ficais no entusiasmo, mais ou menos vago, das vocações correntes. O que sentis, o que manifestais, é uma paixão obsessiva pela história que de tal modo vos absorve, que não sei se não sonhais com ela. Receio muito que os vossos pesadelos incluam a presença hierática de Varnhagen ou o riso escarninho de Capistrano de Abreu. 
Será que Dona Lêda Boechat Rodrigues, vossa ilustre companheira, não chegou a ter ciúmes dessa outra paixão absorvente de vossa vida? O certo é que tivestes uma boa inspiração, conseguindo que se inoculasse também nela, o virus que vos havia invadido. A história se tornou assim, em vossa casa, uma divindade familiar, o que vos garantia uma harmonia perfeita e até mesmo, o que já parecia difícil, um ambiente de idílio em tôrno de assuntos graves e sérios. Há namorados que precisam de poetas e buscam inspiração em expansões alheias. Vós vos contentais com alguns nomes severos, Ranke, Burckhardt, Henri Pirenne...

Ganhastes, assim uma colaboradora de tôdas as horas, dotada de um espírito crítico minucioso e avisado, exercitado nos critérios da heurística como o está mostrando nos volumes já publicados sôbre a história de nosso tempo, através da vida e da presença do Supremo Tribunal Federal. Obra executada com uma proficiência incomum e uma personalidade inconfundível. O que acabou aumentando vossas responsabilidades, quando a crítica se instalou assim em vossa casa, com um jeito afetuoso, que não lhe dissimula a profundeza, nem o acêrto dos reparos. De tal modo se identificaram os vossos espíritos, nessa tarefa, e tão profunda é a vossa comunhão afetiva, que tenho até receio de falar em crítica. Não tereis descoberto dessa forma, uma nova modalidade de auto-crítica?

Não sei bem como e quando se manifestou essa vocação de historiador. Duvido que houvesse necessidade de algum teste. Ou a presença da influências ecológicas, tão famosas quanto desencontradas. Sabemos, por exemplo, que os historiadores brasileiros de maior renome eram, quase sempre, filhos de outros Estados. E não parecia provável o advento de uma carioca, num Estado que mal conseguimos distinguir, entre os mineiros, pernambucanos e gaúchos que o habitam e o governam. Mas desafiastes todos êsses obstáculos, com uma circunstância inesperada. E' que estais ligado aos primeiros povoadores da cidade, com atestado e tudo, e a firma idônea do presidente do Colégio Brasileiro de Genealogia, o engenheiro Carlos Rheingantz. Porque descendeis de André Vilalobos da Silveira, açoreano, que viera para o Rio, em companhia da espôsa, antes de 1600 e a que estais ligado por intermédio dos Teles Barreto de Menezes, e de uma famosa gleba de Jacarepaguá. Aspectos a que não pode ser indiferente, um historiador que pode avaliar bem o que representam êsses vínculos velhos, êsses vínculos velhos de mais de três séculos.

Não sei até que ponto essa antigüidade concorreu para a formação do historiador. Sei que por essa, ou por outra qualquer razão, a vossa vocação se foi aos poucos definindo. Tudo fácil, natural, espontâneo, como se houvesse até mesmo um sinal de predestinação. 
Mas também ainda sem uma consistência mais profunda sem uma definição inapelável. Até que um dias encontrastes um homem chamado William Berrien, professor da Universidade de Harvard e que aqui viera com a missão de ajudar a publicação de guias bibliográficos, indispensáveis aos estudantes brasileiros. Deve-se ao trabalho que êle então executou a publicação, em colaboração com Rubens Borba de Morais, e Francisco de Assis Barbosa, do Manual Bibliográfico de Estudos Brasileiros, instrumento indispensável de orientação e de crítica. William Berrien levou mais longe a sua tarefa: observou alguns jovens brasileiros e designou três dêles para bolsistas em universidades norte-americanas. A fim de que se possa verificar o "ôlho clínico" dêsse selecionador experiente, recordemos que um dos escolhidos foi Joaquim Matoso Câmara, que dentro em pouco se assinalaria no primeiro plano da filologia brasileira. O outro foi José do Prado Valadares, autoridade em assuntos de museus e arquivos, a serviço da Universidade da Bahia. Bem, o terceiro... O terceiro "foi aquêle a quem Tereza deu a mão", e eu teria dito isso cantando se tivesse alguma voz e não corresse o risco de que não chegásseis a perceber a minha intenção.

Já havieis publicado, em 1940, com Joaquim Ribeiro, o livro Civilização Holandesa no Brasil, primeiro prêmio de erudição nesta Academia de Letras. Mas foi depois disso que estivestes nos Estados Unidos e conhecestes os Departamentos de História de algumas excelentes univeridades. Acompanhastes cursos memoráveis como os de Joaquim Barzum, mestre de pesquisas, Henry Steele Commager, especializado em história dos Estados Unidos, Allan Nevins, estudioso de temas políticos, Frank Tennenbaum, dedicado a questões da América Latina, L. Thorndike, autoridade em história medieval, Westermann, professor de história antiga, sem falar no professor Cole, que ensinava metodologia e história econômica e social. A convivência, os trabalhos de seminário, a conversa extra-escolar com os professôres, as pesquisas nas bibliotecas, facilitadas por uma organização bibliográfica prática e eficiente, encontraram de vossa parte uma receptividade entusiástica. Ganhastes, por assim dizer uma nova consciência científica, em centros universitários responsáveis.

\section{Um professor de holandês.}

Conhecestes, então, um professor de Língua e Literatura Holandesa, que ia ter um papel importante em vossa formação profissional. Chamava-se A. J. Barnouw e ensinava na Universidade de Colúmbia. Ofereceu-se para vos ensinar o idioma holandês, num curso 
que continuareis depois com frei Agostinho Keisers, aqui no Rio, no convento dos capuchinhos da Lapa. Um dia, o professor Barnouw viu em vossas mãos um pequeno jornal redigido em língua portuguêsa, editado numa colônia de pescadores lusos do Massachussetts. Pediu-vos o jornal, adiantando que nunca havia tido um texto em português diante dos olhos e começou a ler, quase correntemente. De repente, estacou. Havia uma palavra que não conseguia entender, a palavra bezerra. Surpreendido com a facilidade da leitura, ficastes à espera de uma explicação, que o professor vos deu de ịmediato. Estudara latim nove anos intensamente, e por isso não encontrava dificuldades no texto em português. Se houvesse lido Camões, poderia ter recordado que a língua portuguêsa, "quando imagina, com pouca corrupção crê que é a latina". O obstáculo em que êle estacara, Matoso Câmara vos explicaria depois. Bezerra não era latim puro. Quanto muito, poderia ter-se incorporado ao latim bárbaro da peninsula ibérica. Estava, pois, salvo o admirável curso de latim do professor Barnouw.

Quem vos acompanha desde essa fase, sr. José Honório, verifica a admirável coordenação de vossos estudos. Vossa preparação torna-se sistemática, dentro de uma ordenação de ccnhecimentos e de documentação. Segui vossas pesquisas em tôrno da história do açúcar, na autarquia, a que vos havia levado vosso amigo Miguel Costa Filho. Acompanhei a publicação de vossa magnífica Historiografia e Bibliografia do Domínio Holandês do Brasil, dedicado ao vosso professor de holandês da Universidade de Colúmbia, o professor Barnouw. Já nêsse volume, aproveitáveis as pesquisas feitas em algumas das mais importantes bibliotecas dos Estados Unidos. E começáveis a dizer, no prefácio do livro, o que ia ser uma constante em vossas obras, que a lista de agradecimentos "nunca estaria completa, se nela não confessasse que o maior apôio e principal ajuda veiu de minha mulher, a quem cabe imensa parte dêste livro".

Por isso mesmo que já sabieis o que era o obstáculo da escassez de bibliografias, publicastes, por intermédio do Instituto Pan-americano de Geografia e História, dois livros excelentes, a Bibliografia del Brasil - Siglo XVI e Historiografia del Brasil - Siglo XVII. Divulgastes, em seguida, os volumes de índices anotados da Revista do Instituto do Ceará e da Revista do Instituto Arqueológico de Pernambuco. Ainda no vosso ativo de divulgador, devemos incluir os 39 volumes dos Documentos de História da Biblioteca Nacional, iniciadas no govêrno de Washington Luís e completadas com os volumes excelentes, com que se esclarece a história da revolução pernambucana de 1817. Não seria possível omitir, nessa relação, o esfôrço imenso, para reunir e publicar os três volumes da Correspon- 
dência de Capistrano de Abreu, o Catálogo da Coleção Visconde do Rio Branco, as edições críticas de Nieuhof e os Capítulos de História Colonial. Ao contrário de Melo Morais, que queimava os documentos que ia publicando, para que ninguém mais os pudesse encontrar, procurastes tornar mais fácil a tarefa dos epígonos, numa benemerência quase de escoteirismo.

Teoria da História do Brasil.

Aqui, sr. José Honório, vamos caminhando para as vossas obras fundamentais. A começar pela vossa Teoria da História do Brasil, já em terceira edição. O professor Oliveira França, da Universidade de São Paulo, observou que "ninguém ainda no Brasil dispôs de tão copiosa bibliografia especializada". Vosso amigo, o Professor Iglésias, da Universidade de Belo Horizonte, viu no vosso livro um sinal de que já havíamos "chegado à maturidade, que caracteriza alguns centros universitários". O professor Charles Nowell, da Universidade de Illinois, considerou vosso livro, não apenas uma introdução ao método histórico, como também um guia bibliográfico, destinado aos estudantes brasileiros de nível superior. Damião Peres, o mestre português, acha que o vosso livro é a "primeira publicação de seu gênero em língua portuguêsa". E a êsses louvores vieram juntar-se outros. Sabeis o que me parece mais significativo? $O$ do nosso companheiro Afonso de Taunay, o trabalhador infatigável, que depois de haver publicado os 11 volumes da História das Bandeiras e os 14 volumes da História do Café, ainda se considerava "assombrado" com o esfôrço, que o vosso trabalho vos havia custado.

E eram homens familiarizados com as obras de circulação universal. Mas acrescentáveis a tôdas elas, não apenas a informação bibliográfica excelente, uma metodologia esclarecedora, como uma filosofia da história, documentada e segura, dando sempre uma palavra informativa, mesmo em face de trabalhos recentes. Só o que não compreendo é que a vossa obra seja de um out-sider e não de um professor de metodologia histórica em alguma de nossas universidades. Mas sabemos que no Brasil as cousas são assim mesmo. Supristes, na verdade, os títulos universitários com o mérito de vossos trabalhos.

Depois da Teoria da História do Brasil, tendes uma série de monografias notáveis, como História e Historiadores do Brasil, Vida e Historia, O Continente do Rio Grande e Notícia de Vária História, em que se contém o vosso magnífico ensaio a respeito do livro, em que Max Weber estuda a influência da ética protestante no desenvolvimento do capitalismo. Uma das obras dessa fase. A Pesquisa 
Histórica no Brasil, acaba de ser refundida e ampliada numa nova edição, de certa forma complementar de vossa Teoria da História do Brasil, para servir de fundamento a um de vossos pleitos mais ardentes, qual seja o da criação do Instituto Nacional de Pesquisa Histórica a exemplo de instituições, que encontrastes em alguns países mais avançados, do domínio da cultura histórica.

Mas o que desejo realçar são os vossos livros da última fase, aquêles em que se sente a presença do scholar, no retrato famoso que dêles Emerson nos deixou, descrevendo-o como servidores, e mestres, de uma universidade sem fronteiras. Refiro-me aos vossos livros África e Brasil, 1961, Aspirações Nacionais, 1962, Conciliação e Reforma no Brasil, 1965, Interêsse Nacional e Politica Externa, 1966. Obras realmente notáveis, sobretudo quando definis os deveres do Brasil em face de um colonialismo, de que há mais de um século nos libertamos, ou acreditamos nos libertar.

Seria agradável, para mim, deter-me em todos êles, até mesmo para que sentíssemos os pontos de convergência e de discordância. Acho, às vêzes, permiti que $\cdot$ o diga, alguma cousa, não direi bem de radicalismo, mas de categórico, em algumas de vossas afirmações. Uma certeza que não deixa margem para uma dúvida discreta e receosa. Não vos diria isso por escrito, pois que também gosto de admitir, e de justificar, diferenças de temperamento e de idade.

\section{$O$ caso de Tavares Bastos.}

Vêde o caso de Tavares Bastos. Vosso elogio não poderia ter sido mais caloroso. E segundo penso se a vida de Tavares Bastos se encerrou aos 36 anos, não sei como recusar o vosso entusiasmo, e a vossa intenção de afastar restrições, que pudessem atingir tão vibrante apóstolo da liberdade, num país que tanto precisa dêles. Mas eu acabo voltando aos meus pendores íntimos. Não me considero excessivamente severo, mas gosto das igrejas com poucos altares. E Tavares Bastos defendia não apenas as liberdades políticas, em que todos estamos de acôrdo, como a liberdade econômica, que então compendiava os interêsses da Inglaterra, da Inglaterra pela qual Tavares Bastos manifestava um entusiasmo "frenético", são expressões dêle, que acabais de recordar. Em conseqüência da campanha que êle sustentou, acabou-se com a nacionalização da cabotagem no Brasil, e não era possível concorrer, em igualdade de condições, com a marinha mercante de uma nação, que obtinha o carvão de Cardiff por um preço, na verdade inaccessível a todos os países concorrentes. 
Em poucos anos, revelaram-se desastrosos os resultados da medida - o "malôgro" de que falastes. E de tal maneira se patentearam, êsses inconvenientes, que a Constituinte Republicana se apressou a incluir, no texto da própria Constituição, a nacionalização de cabotagem, que não deveria ter sido suprimida. Foram oficiais de nossa Marinha de Guerra, que defenderam essa causa na Constituinte, para a defesa de nossa marinha mercante. Não se ignorava, aliás, que na Inglaterra a expansão de sua marinha se baseara em leis protetoras, que vinham de Ricardo II, em pleno século XIV.

Tavares Bastos falava, também, na ausência de uma tradição marítima no Brasil sem chegar a ver que era uma consequiência da impossibilidade de possuir marinhas mercantes. Não sei o que agora poderia êle dizer, se pudesse ter lido as Palavras ao Mar, de Vicente de Carvalho, a literatura marinhista de Virgílio Várzea, as tradições dos jangadeiros do Nordeste ou dos pescadores de Dorival Caimi.

\section{$O$ historiador participante.}

Mas são reparos por alto, que não atingem vossos livros, pois que não afetam o mérito intrínseco das teses que sustentais. $E$ os livros a que me referi, por mais que meçamos os adjetivos, revelam um grande pensador político. Até mesmo porque a História já se transformou em vossas mãos. De um espectador mais ou menos indiferente ou distante, passais a uma atitude participante, que complementa vossa concepção historiográfica .

Êsses livros da nova fase, mais que a Teoria da História do Brasil, vão interessando profundamente os especialistas estrangeiros, pelo soma de originalidade e de personalidade que revelam. $O$ Brasil $e$ a África foi traduzido para o inglês sob os auspícios da Universidade da Califórnia. A Universidade do Texas promoveu a edição de $A s$ Aspirações Nacionais. O livro sôbre a Âfrica teve o prefácio de Allan Manchester, com um estudo a vosso respeito à altura da proficiência do melhor historiador da preeminência inglêsa no Brasil. Bradford Burns apresenta, com o entusiasmo ardente de sua juventude extrovertida, o volume sôbre As Aspirações Nacionais. E o número de comentadores estrangeiros cresce, dia a dia. $\mathrm{Na}$ Inglaterra, o Instituto de Pesquisa Histórica vos convidou para um almôço honrado com a presença de algumas das grandes figuras da historiografia inglêsa: J. G. Edwards, presidente do Instituto e mais Arnold Toynbee, Charles Boxer, Charles Webster, Robin Humphreys e J. Passant. Nosso bri- 
lhante patrício, Artur José Poerner, que se encontra na Inglaterra, surprende-se com a extensão de vossa notoriedade, nos meios universitários de Oxford. E o registro bibliográfico de vossas obras tem assinaturas prestigiosas, como as de Raymond Carr, da Universidade de Oxford, e de estudiosos como Richard A. Mazzara, Henry Benstein, James Duffy, Roger Ausley. Na Revista de História da América, os críticos vos colocam ao lado de Varnhagen e de Capistrano de Abreu. E a Histoire Universelle, edição de La Plêiade, dirigida por $\mathrm{R}$. Grousset e Léonard, proclamam o vosso mérito como "excelente historiador".

Vossa orientação e vossa doutrina, defendida em diversos livros e estudos, foram sintetizados no capítulo primeiro de História e Historiadores do Brasil, sob o título A Historiografia Brasileira e o Atual Processo Histórico, assim como em alguns itens da Teoria da História do Brasil.

$\mathrm{Na}$ vossa concepção, a história se reescreve a todos os instantes, sob critérios que são impostos pelas condições atuais e não pelos interêsses e preocupações do passado. Com Dilthey e Rickert aceitais a diferenciação fundamental, entre ciência natural e ciência cultural. Mas com Troeltsch, Meinecke e Benedetto Croce, vos incorporais ao historicismo - o historicismo que, no entender de Croce, é o próprio humanismo.

A essa conclusão se prendem vários corolários. Como o de que a história é irreversível. O de que a história ajuda a compreender o presente. $\mathrm{O}$ de que ela é dos vivos e não dos mortos, pois que se liga mais ao presente ou às necessidades do presente do que às proprias limitações do passado. O que vale dizer que a história é sempre inseparável do historiador, com que se abre campo ao seu subjetivismo e consequientemente, ao seu idealismo. Para que através dêsses processos se alcance a superação do passado, numa espécie de catarse, com a purgação e a purificação por meio do conhecimento histórico. Valery ironizava: - Nous entrons dans l'avenir à reculons. Porque não ficar de olhos fitos no futuro? Exorcitando tôdas as manifestações e processos de alienação? Uma História que nos libertasse do passado, mas que nos preparasse para o futuro. Catarse e sublimação.

Mas o Historicismo não é filosofia de fácil circulação. O transcendente não desiste de suas interrogaçốes teimosas, a que o próprio Croce procurava fugir falando num "historicismo absoluto". Mas dissolver o incognoscível spencereano no Historicismo, não seria uma solução. Pareceria antes uma evasiva. Não será o historicismo, em grande parte, uma filosofia de e para historiadores? 


\section{Necessidade do Estudo da História.}

Mas o interêsse da História não depende de sua capacidade ou de sua ampliação como metafísica. Por isso o discutido Toynbee, em conferência pronunciada na Universidade do Recife, enumerava as razões pelas quais se devia estudar a história. Contava o episódio de uma reunião social em que os convivas, todos êles historiadores, entenderam comentar a vida, os erros, os crimes e os vícios dos Imperadores romanos da Antigüidade. A dona da casa, aflita com o rumo da conversa aproveitou a primeira pausa para perguntar, aos seus convidados, se aquelas pessoas, de que tanto falavam não eram uma galeria de marginais. Como a resposta fôsse afirmativa, ela ainda indagou se não estavam todos mortos. A uma nova afirmativa decidiu, peremptória: - "Pois então não falemos mais dessa gente que não merece nossa atenção". Mas a História, prevenia Toynbee é indispensável para fazer compreender o mistério da vida. E o destino dos homens. Uma história criada para o homem, e não o homem para a história.

Por isso vos convocamos, sr. José Honório. E quando vos convocamos, já sabiamos que virieis como pastor e não como mercenário na linguagem de Duarte Coelho. Os tempos são cada vez mais difíceis, o trabalho mais ingente. Precisamos de homens como vós com a vossa inteireza e o vosso destemor. Para esclarecer consciências. Para animar vontades. Para dizer o que acabastes de dizer e que outro historiador brasileiro havia sintetizado uma fórmula perfeita quando escrevia - são palavras de Oliveira Lima - que "a própria História da Civilização era, em resumo, a história da luta da liberdade contra o despotismo e o da igualdade contra o privilégio".

Não há tarefa maior do que a de trabalhar, para que o nosso país nunca deixe de ser a pátria de que se possam orgulhar as gerações do futuro. Sentimos a ansiedade dos moços, as interrogações que queimam suas pupilas. E que podemos dizer-lhes nessa prestação de contas, diante de um tribunal que não sabe e que não poderá perdoar, porque julga interêsses e aspirações do Brasil?

Vinde pois, sr. José Honório, vinde cooperar conosco, em busca das respostas que nos redimam. Vinde trabalhar pelo Brasil, como um historiador que busca no passado, e no presente as respostas, que o futuro nos reclama. 